\title{
Relato de caso: Diagnóstico de lesão traumática em corpo parcialmente carbonizado
}

\author{
Case report: Traumatic lesion diagnosis \\ in partially carbonized body
}

\author{
Mariana da Silva Ferreira*, Talita Zerbini*, Victor Alexandre Percinio \\ Gianvecchio $^{\star *}$, Mario Jorge Tsuchiya ${ }^{\star \star *}$, Daniel Romero Muñoz ${ }^{\star \star \star *}$
}

\begin{abstract}
Ferreira MS, Zerbini T, Gianvecchio VAP, Tsuchiya MJ, Muñoz DR. Relato de caso: Diagnóstico de lesão traumática em corpo parcialmente carbonizado. Saúde, Ética \& Justiça. 2008;13(1)42-5.

Resumo: Relato de exame necroscópico realizado em indivíduo adulto do sexo masculino, desconhecido, que apresentava carbonização parcial e raras áreas de pele intacta. No crânio verificou-se hematoma subdural, no tórax, presença de lesões pérfuro-incisas com hemotórax e, no abdômen, uma rotura da parede gástrica na grande curvatura. A morte foi decorrente da associação de traumas torácico e craniencefálico, conseqüentes à ação de instrumentos contundentes e pérfuro-cortante, com carbonização pós-mortal.
\end{abstract}

Descritores: Ferimentos e lesões. Queimadura. Autopsia. Causas de morte.

INTRODUÇÃo

$\mathrm{N}$ as queimaduras de quarto grau ou carbonização, segundo a classificação de Hoffmann, a alta temperatura gera redução parcial ou total dos te-cidos. Isto causa alterações frequentes, tais como a posição de pugilista (devido a retração tecidual), fraturas de ossos longos e de calota craniana, abertura de cavidades torácica e abdominal com exposição visceral, destruição total de extremidades e de partes moles superficiais, pre- sença de hematoma extra-dural e sub-dural e áreas de calcinação(1-2).

A necropsia em corpos carbonizados é considerada de alta complexidade e, até mesmo, um desafio médicolegal, face às dificuldades para identificar as lesões, classificá-las em vitais ou pós-mortais, determinar a causa da morte, e proceder à identificação do cadáver, que ganha especial relevância nesses casos

São métodos legalmente aceitos, a identificação

* Residentes em Medicina Legal da Faculdade de Medicina da Universidade de São Paulo.

** Preceptor da Residência em Medicina Legal da Faculdade de Medicina da Universidade de São Paulo.

*** Médico legista do Instituto Médico Legal de São Paulo.

${ }^{\star \star \star *}$ Professor titular do Departamento de Medicina Legal, Ética Médica e Medicina Social e do Trabalho da Faculdade de Medicina da Universidade de São Paulo e coordenador da residência médica em Medicina Legal da FMUSP.

Endereço PARA CORRESPONDÊnCIA: Daniel Romero Muñoz. Instituto Oscar Freire. Faculdade de Medicina da USP. Rua Teodoro Sampaio, 115. São Paulo, SP. CEP: 05405-000. E-mail: danielmunoz@ bol.com.br 
judiciária, constituída pela dactiloscopia e pelo reconhecimento direto, e a identificação médico legal por meio de estudos antropológico, odontológico e radiológico, que estabelece elementos gerais de identificação como sexo, faixa etária, faixa estatural, raça, e elementos individualizadores como presença de próteses, órteses, fraturas com ou sem síntese, manipulações odontológicas, etc., podendo, se necessário, chegar até a análise genética (exame de DNA).

$\mathrm{Na}$ ação do fogo deve-se ter em mente dois efeitos: o térmico, com as alterações destrutivas, e o químico, com a ação do monóxido de carbono. Vestígios de fuligem podem ser verificados em vias respiratórias ao exame macroscópico ou microscópico e a detecção de monóxido de carbono em sangue e vísceras através de exame laboratorial, constituem-se em elementos importantes para confirmar se o indivíduo estava vivo quando da ação do fogo, podendo ser fator determinante para o diagnóstico da causa de morte ${ }^{(3)}$.

Quanto ao diagnóstico jurídico, a ação do calor direto tem como principal etiologia o acidente, mas não é excepcional a relação com suicídio ou mesmo com o crime de homicídio(1). Em literatura internacional, a carbonização é atribuída principalmente a causas acidentais. Em estudo realizado em Lyon, na França, no período de 1993 a 2003, com 40 vítimas de ação de fogo, a incidência de acidentes foi de $50 \%$, homicídios $30 \%$ e suicídios $15 \%{ }^{(4)}$. Em Lubeck, na Alemanha, estudo com 115 vítimas, no período de 1990 a 1999, revelou a incidência de $60,8 \%$ de acidentes, $14,8 \%$ de homicídios e $16,5 \%$ de suicídios ${ }^{(5)}$. Em outro estudo realizado na Alemanha, em Freiburg, no período de 1996 a 2002 com 88 vítimas de fogo, 66\% corresponderam a acidentes, $23 \%$ a suicídios e $6 \%$ a homicídios ${ }^{(6)}$.

\section{Descrição - Exame Necroscópico}

Exame necroscópico em cadáver de adulto desconhecido, do sexo masculino, encontrado em via pública, encaminhado ao IML por autoridade policial, sem informações adicionais.

Ao exame externo, o corpo apresentava extensas queimaduras e carbonização parcial em cabeça, tó-rax, abdômen, membros e extremidades, restos de cabelos ulótricos/cimótricos, restos de pele de cor parda, sem sinais vitais de queimadura e na cabeça foram verificados hematomas na musculatura supraorbitária esquerda e parietooccipital esquerda, sem sinais de fratura. Não se identificou lesão na parede externa devido ao grau de carbonização. Foram realizadas radiografias do corpo todo, que não revelaram a presença de material radiopaco, como projétil de arma de fogo, ou alterações ósseas de interesse médico legal para fins de identificação. Os polegares foram encaminhados ao Instituto de Identificação para tentativa de coleta de impressão dactiloscópica, com sucesso, havendo o aproveitamento do dac-tilograma correspondente ao polegar direito, o qual ficou arquivado.

Ao exame interno, na cavidade craniana observouse extenso hematoma subdural parieto-temporal direito, sem sinais de fratura; a cavidade torácica apresentava discreta equimose retroesternal e subdiafragmática, com extensa coleção hemorrágica na cavidade pleural à esquerda (hemotórax); os pulmões encontravam-se hemorrágicos, com lesão pérfuro-incisa transfixando o lobo inferior do pulmão esquerdo, no seio costo-frênico esquerdo, junto ao gradeado costal, constatou-se presença de lesão pérfuro-incisa medindo cerca de $2,5 \mathrm{~cm}$ de extensão, com projeção na linha axilar média e na cúpula diafragmática esquerda observaram-se duas lesões péfuro-incisas, medindo respectivamente $1,5 \mathrm{~cm}$ e 2,0 cm de extensão; o coração estava com as cavidades vazias e sem lesões traumáticas de interesse médico legal; na abertura da traquéia e dos brônquios principais não foram encontrados sinais de fuligem ou corpos estranhos; na cavidade abdominal observou-se uma rotura da parede gástrica na grande curvatura, com saída de restos alimentares sólidos e sem reação peritoneal macroscopicamente. As demais vísceras não apresentaram lesões traumáticas de interesse médico legal.

\section{Discussão e Conclusão}

Apesar da etiologia jurídica das lesões pelo calor direto ser geralmente acidental, como ocorre em incêndios de casas e prédios, explosões de materiais combustíveis, acidentes de trânsito e acidentes aéreos, o uso do fogo pelo criminoso como instrumento lesivo também é observado em homicídios e lesões corporais. O fogo também pode ser usado em casos de suicídio pela queima das vestes, embebidas em álcool ou gasolina ${ }^{(7)}$. 


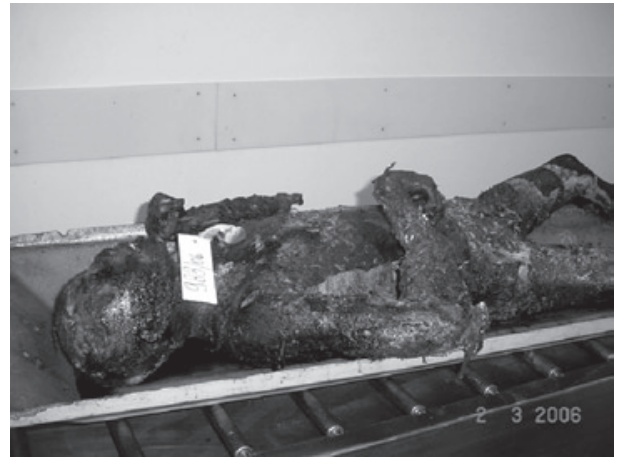

Figura 1. Corpo com carbonização parcial

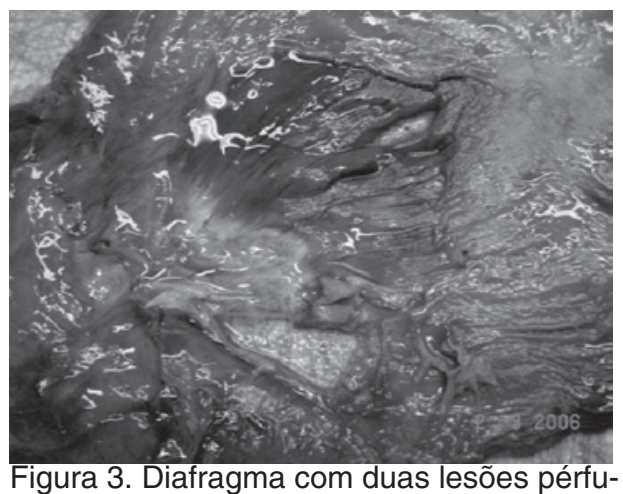
ro-incisas.

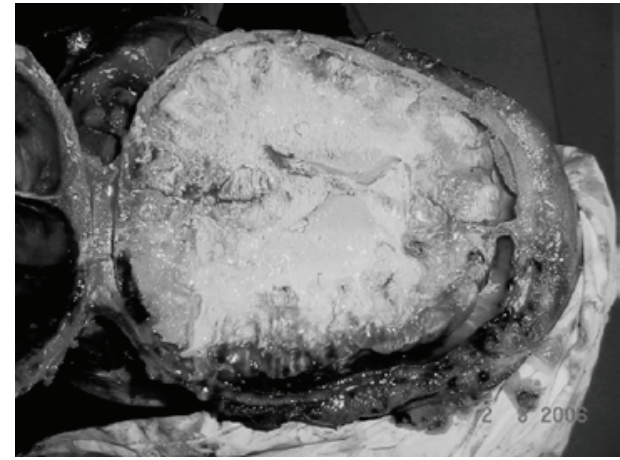

Figura 2. Hematoma subdural em região parieto-tem-poral direita.

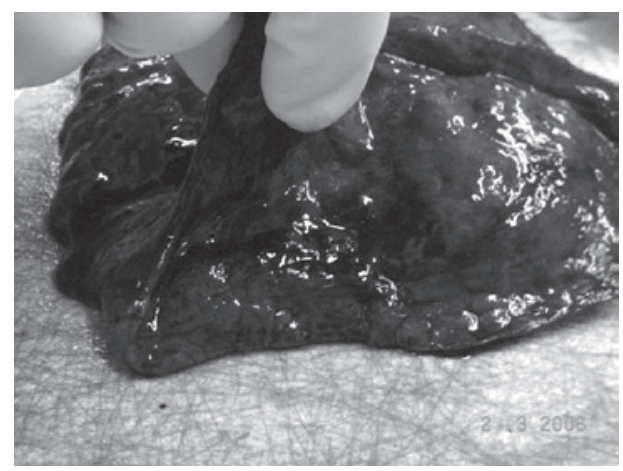

Figura 4. Base do pulmão esquerdo com lesão pérfuro-incisa
Em casos de crime, o perito pode se deparar com uma simulação, ou seja, a morte pode ser criminosa e as condições do cadáver e do ambiente preparadas para indicar um suicídio(1). Nestes casos a multiplicidade de lesões não é incomum e o fogo atua sobre os corpos com o objetivo de mascarar lesões corporais ou destruir total ou parcialmente regiões com potencial de identificação, como impressões digitais e face ${ }^{(8)}$.

Torna-se essencial ao exame necroscópico a determinação de todas as lesões existentes e sua vitalidade, para que seja possível estabelecer em que momento ocorreu a ação do fogo e a provável intenção dessa ação, principalmente na simulação de acidente ou dissimulação de um homicídio, podendo orientar o judiciário para o diagnóstico da causa jurídica da morte ${ }^{(9)}$.

No presente caso, o corpo apresentava carbonização parcial, com raras regiões de pele intacta. Apesar de se tratar de desconhecido e do grau de destruição do corpo, será possível uma identificação futura, caso surja alguma suspeita relacionada à identidade, face ao sucesso na coleta de impressão digital do polegar direito, a qual foi arquivada.

A presença de hematomas na musculatura das regiões supra-orbitária e parieto-occipital esquerda da cabeça, e do hematoma subdural localizado na região parieto-temporal direita, indica a ação de instrumento contundente, sendo que a localização do hematoma intracraniano sugere que tenha ocorrido lesão por contragolpe.

As lesões descritas no tórax, que atingem parede torácica, pulmão esquerdo, diafragma e estômago, indicam a ação de instrumento pérfuro-cortante, atuando da esquerda para direita e de baixo para cima. O hemotórax descrito indica hemorragia interna traumática aguda que, em associação com o hematoma subdural, justifica o mecanismo de morte.

A ausência de reação vital na pele associada à ausência de fuligem em via aérea e de monóxido de carbono no sangue indicam que a carbonização/ queimadura ocorreu após a morte, sendo possível a inferência de uma relação com ato criminoso, ou seja, o indivíduo foi morto e logo após queimado, possivelmente para ocultação de lesões ou da própria identidade. 
Um exame pericial bem feito e minucioso ganha maior importância em casos de carbonização, principalmente pelo fato de o comprometimento estrutural do cadáver ser extenso e haver grande dificuldade para se localizar a sede das lesões e para se determinar os respectivos agentes causadores.

Ferreira MS, Zerbini T, Gianvecchio VAP, Tsuchiya MJ, Muñoz DR. Case report: Traumatic lesion diagnosis in partially carbonized body. Saúde, Ética \& Justiça. 2008;13(1):41-5.

AвStRAct: Report of a necroscopic exam performed in an male adult whose identity was unkown. The body had partial carbonization and rare areas of intact skin. The skull contained subdural hematoma and the chest showed an stab wound and hemothorax. In the abdominal cavity it was found a rupture of the stomach wall in the great curvature. The cause of death was the combination of chest and head trauma as a consequence of blunting and stabbing instruments action, with carbonization occurring after death.

Keywords: Wounds and injuries. Burns. Thermal effects. Necroscopic exam in burned bodies. Cause of death. Autopsy.

Artigo recebido em 13/03/2008.

Aprovado em 15/04/2008.

\section{REFERÊNCIAS}

1. Fávero F. Medicina legal. 12a ed. Belo Horizonte: Ed. Villa Rica; 1991

2. França GV. Medicina legal. 7a ed. Rio de Janeiro: Guanabara Koogan; 2004.

3. Del-Campo ERA. Medicina legal. 3a ed. São Paulo: Saraiva; 2007.

4. Fanton L, Jdeed K, Coartet S, Malicier D. Criminal burning. Forensic Sci Int. 2006;158;87-93.

5. Gerling I, Meissner C, Reiter A, Oehmichen M. Death from thermal effects and burns. Forensic Sci Int. 2001;115;33-41.
6. Bohnert M, Werner CR, Pollak S. Problems associated with the diagnosis of vitality in burned bodies. Forensic Sci Int. 2003;135:195-205.

7. Carvalho HV, et al. Compêndio de medicina legal. São Paulo: Saraiva; 1987.

8. Coelho CAS, Jorge Jr JJ, et al. Manual técnicooperacional para os médicos-legistas do Estado de São Paulo. São Paulo: Conselho Regional de Medicina do Estado de São Paulo; 2008.

9. Croce D, Croce Jr. Manual de medicina legal. 4a ed. São Paulo: Saraiva; 1998. 